\title{
Common Consumer Health-Related Needs in the Pediatric Hospital Setting: Lessons from an Engagement Consultation Service
}

\author{
Daniel J. Lee ${ }^{1,2}$ Robert Cronin $2,3,4$ Jamie Robinson ${ }^{2,5}$ Shilo Anders ${ }^{6}$ Kim Unertl ${ }^{2}$ Katherine Kelly ${ }^{4}$ \\ Heather Hankins ${ }^{7}$ Ryan Skeens ${ }^{4}$ Gretchen P. Jackson ${ }^{2,4,8}$
}

\footnotetext{
${ }^{1}$ Department of Urology, Vanderbilt University Medical Center, Vanderbilt University, Nashville, Tennessee, United States

2 Department of Biomedical Informatics, Vanderbilt University Medical Center, Vanderbilt University, Nashville, Tennessee, United States

${ }^{3}$ Department of Internal Medicine, Vanderbilt University Medical

Center, Vanderbilt University, Nashville, Tennessee, United States

${ }^{4}$ Department of Pediatrics, Vanderbilt University Medical Center,

Vanderbilt University, Nashville, Tennessee, United States

${ }^{5}$ Department of Surgery, Vanderbilt University Medical Center, Vanderbilt University, Nashville, Tennessee, United States

${ }^{6}$ Department of Anesthesiology, Vanderbilt University Medical Center, Vanderbilt University, Nashville, Tennessee, United States

7 Surgical Outcomes Center for Kids, Vanderbilt University Medical Center, Vanderbilt University, Nashville, Tennessee, United States

8 Department of Pediatric Surgery, Vanderbilt University Medical

Center, Vanderbilt University, Nashville, Tennessee, United States
}

Address for correspondence Daniel J. Lee, MD, Department of Urology, Vanderbilt University Medical Center, A1302 Medical Center North, Nashville, TN 37232, United States (e-mail: Daniel.Lee.1@Vanderbilt.edu).

Appl Clin Inform 2018;9:595-603.

\section{Abstract}

Keywords

- patient engagement

- activation

- health information technology

- patient portal

- mobile apps
Background Informed and engaged parents may influence outcomes for childhood illness. Understanding the needs of the caregivers of pediatric patients is a critical first step in promoting engagement in their child's care. In 2014, we developed an Engagement Consultation Service at the Monroe Carell Jr. Children's Hospital at Vanderbilt. This service determines the health-related needs of the caregivers of hospitalized children and makes educational or technology recommendations to meet those needs and support engagement.

Objectives This report describes the most common health-related needs identified in the caregivers of hospitalized pediatric patients and details the recommended interventions to meet those needs.

Methods The most commonly reported consumer health-related needs from our 3year experience with the Engagement Consultation Service were extracted from consultations notes. Each need was classified by semantic type using a taxonomy of consumer health needs. Typical recommendations for each need and their administration were detailed.

Results The most frequently recognized needs involved communicating with health care providers after discharge, using medical devices, distinguishing between benign and concerning symptoms, knowing what questions to ask providers and remembering them, finding trustworthy sources of information online, understanding disease received

February 22, 2018

accepted after revision

June 16, 2018 (c) 2018 Georg Thieme Verlag KG Stuttgart · New York
DOI https://doi.org/

10.1055/s-0038-1667205. ISSN 1869-0327. 


\begin{abstract}
prognosis, and getting emotional support. A variety of apps, Web sites, printed materials, and online groups were recommended.

Conclusion The parents of hospitalized patients share several common health-related needs that can be addressed with educational and technology interventions. An inpatient Engagement Consultation Service provides a generalizable framework for identifying health-related needs and delivers tools to meet those needs and promote engagement during and after hospitalizations.
\end{abstract}

\section{Background and Significance}

In 2001, the Institute of Medicine recommended that patient engagement should be a major emphasis in health care practice and policy. ${ }^{1}$ Patients who have more active roles in their health and care have improved clinical outcomes, ${ }^{2-4}$ increased satisfaction, ${ }^{5,6}$ improved understanding of their care, ${ }^{7,8}$ and decreased costs. ${ }^{9,10}$ Informed and self-efficacious parents have an important role in the outcomes of pediatric patients. ${ }^{11-14}$ In the United States, 35 million annual inpatient admissions offer opportunities for interventions to support engagement. ${ }^{15}$ Understanding the needs of patients and caregivers is a critical first step in supporting their engagement. ${ }^{16}$

In 2014, the Vanderbilt Children's Hospital (VCH) launched an Engagement Consultation Service to support the families of hospitalized children in becoming more engaged in their children's care. The organization of the Engagement Consultation Service and a detailed description of the consultation process has been described elsewhere. ${ }^{17}$ Consultations can be requested by any pediatric inpatient care team and are most commonly sought for families of children with new diagnoses or chronic illnesses. Members of the consultation team meet with the family to assess their sociodemographic characteristics, capacities (e.g., health literacy, numeracy, level of education, and income), technology preferences, and healthrelated needs. Previously validated surveys, semistructured interviews, and forms developed for the consultation service were utilized for the consultation service. The multidisciplinary consultation team, including clinical informaticians, human factors engineers, patient education specialists, surgeons, pediatricians, intensivists, nurses, and complex care team members, then make personalized educational and technology recommendations to meet each need based on patient and caregiver characteristics and technology preferences. A strategy for meeting needs and supporting engagement is developed based on the caregiver's level of activation. ${ }^{18}$ Patient activation is a measure of one's knowledge, confidence, and skills in managing one's health or the health of another. If parents have low levels of activation and are not aware their roles are important, appropriate education is provided. Caregivers with higher levels of activation are given practice with tools to build confidence in undertaking disease-management activities. Recommendations are vetted with the primary care teams and delivered during the hospitalization. A member of the consultation services provides any needed assistance with installation or navigation of tools, as well as practice with their use. The consultation process is iterative. New needs that emerge during hospitalization are addressed, and recommendations or tools that are not deemed helpful to the family are replaced by others.

\section{Objectives}

The objectives of this case report were to identify the most common health-related needs reported by parents of hospitalized pediatric patients and to describe recommendations made by the consultation service to address these needs.

\section{Methods}

The most commonly recognized health-related needs were extracted from two research studies of the Engagement Consultation Service, a retrospective review of the initial experience $^{17}$ and an ongoing prospective study examining whether consultations affect parent activation and health care utilization. These studies were conducted at an academic children's hospital and enrolled adult (i.e., age 18 years or older), Englishspeaking parents or legal guardians of hospitalized patients. Both studies were performed in compliance with the World Medical Association Declaration of Helsinki on Ethical Principles for Medical Research Involving Human Subjects, and were approved by the VCH Institutional Review Board. Two members of the research team (G.P.J. and D.J.L.) identified recurring needs in consultation notes from these research studies and reviewed them with the consultation team to select those representing the most common needs observed during engagement consultations done both within and outside research studies since 2014. The most frequently reported needs occurring consistently over time and for a variety of patient diagnoses were included in this report.

Health-related needs were categorized using a taxonomy of consumer health needs ( - Table 1 ), which has been previously employed to characterize consumer health needs from patient journals, patient portal messages, and engagement consultations. ${ }^{17,19-22}$ This taxonomy separates needs into five main categories: informational, medical, logistical, social, or other. Recommendations that have proven effective in meeting each type of need are described with details of their implementation. 
Table 1 Taxonomy of common needs or communications

\begin{tabular}{|c|c|c|}
\hline $\begin{array}{l}\text { Major } \\
\text { need type }\end{array}$ & Category & Subcategory \\
\hline \multicolumn{3}{|l|}{$\begin{array}{l}\text { Information } \\
\text { need }\end{array}$} \\
\hline & $\begin{array}{l}\text { Normal anatomy and } \\
\text { physiology problems }\end{array}$ & \\
\hline & & Definition \\
\hline & & Epidemiology \\
\hline & & Risk factors \\
\hline & & Etiology \\
\hline & & $\begin{array}{l}\text { Pathogenesis/Natural } \\
\text { history }\end{array}$ \\
\hline & & Clinical presentation \\
\hline & & Differential diagnosis \\
\hline & & Related diagnoses \\
\hline & & Prognosis \\
\hline & Management & \\
\hline & & Goals/Strategy \\
\hline & & Tests \\
\hline & & Interventions \\
\hline & & Sequence/Timing \\
\hline & & Personnel/Setting \\
\hline & Tests & \\
\hline & & Definition \\
\hline & & Goals \\
\hline & & Physiologic basis \\
\hline & & Efficacy \\
\hline & & $\begin{array}{l}\text { Indications/ } \\
\text { Contraindications }\end{array}$ \\
\hline & & Preparation \\
\hline & & $\begin{array}{l}\text { Technique/ } \\
\text { Administration }\end{array}$ \\
\hline & & Interpretation \\
\hline & & Posttest care \\
\hline & & Advantages/Benefits \\
\hline & & Costs/Disadvantages \\
\hline & & Adverse effects \\
\hline & Interventions & \\
\hline & & Definition \\
\hline & & Goals \\
\hline & & Mechanism of Action \\
\hline & & Efficacy \\
\hline & & $\begin{array}{l}\text { Indications/ } \\
\text { Contraindications }\end{array}$ \\
\hline & & Preparation \\
\hline & & $\begin{array}{l}\text { Technique/ } \\
\text { Administration }\end{array}$ \\
\hline & & Monitoring \\
\hline & & Postintervention care \\
\hline & & Advantages/Benefits \\
\hline & & Costs/Disadvantages \\
\hline & & Adverse effects \\
\hline
\end{tabular}

(Continued)
Table 1 (Continued)

\begin{tabular}{|c|c|c|}
\hline $\begin{array}{l}\text { Major } \\
\text { need type }\end{array}$ & Category & Subcategory \\
\hline \multicolumn{3}{|l|}{$\begin{array}{l}\text { Medical needs or } \\
\text { communications }\end{array}$} \\
\hline & $\begin{array}{l}\text { Appointments/ } \\
\text { Scheduling }\end{array}$ & \\
\hline & Medical equipment & \\
\hline & Personnel/Referrals & \\
\hline & Prescriptions & \\
\hline & Problems & \\
\hline & Follow-up & \\
\hline & Management & \\
\hline & Tests & \\
\hline & Interventions & \\
\hline \multicolumn{3}{|l|}{$\begin{array}{l}\text { Logistical needs or } \\
\text { communications }\end{array}$} \\
\hline & $\begin{array}{l}\text { Contact information/ } \\
\text { Communication }\end{array}$ & \\
\hline & $\begin{array}{l}\text { Facility/Policies/ } \\
\text { Personnel }\end{array}$ & \\
\hline & Insurance/Billing & \\
\hline & Medical records & \\
\hline & $\begin{array}{l}\text { Personal } \\
\text { documentation }\end{array}$ & \\
\hline & $\begin{array}{l}\text { Health information } \\
\text { technologies }\end{array}$ & \\
\hline & Tests & \\
\hline & Interventions & \\
\hline & Transportation & \\
\hline & $\begin{array}{l}\text { Life management/ } \\
\text { Balance }\end{array}$ & \\
\hline \multicolumn{3}{|l|}{$\begin{array}{l}\text { Social needs/ } \\
\text { Communications }\end{array}$} \\
\hline & Acknowledgment & \\
\hline & Complaints & \\
\hline & $\begin{array}{l}\text { Emotional need } \\
\text { or expression }\end{array}$ & \\
\hline & $\begin{array}{l}\text { Relationship } \\
\text { communications }\end{array}$ & \\
\hline & Miscellaneous & \\
\hline Other & & \\
\hline
\end{tabular}

\section{Results}

The research team reviewed a total of 169 needs from 32 engagement consultations, 99 needs from 22 consultations described in the previously published study of the initial experience with the consultation service, and 70 needs from 10 consultations in the ongoing prospective study. The study population examined in the initial experience has been reported in detail elsewhere. The 10 consultations from the ongoing prospective study involved 10 adult parents with ages ranging from 19 to 39 years. Nine were female, and one was male; nine were White, and one was African American. The pediatric patients ranged in age from premature neonates to 
11 years. Five patients were female, and five were male; eight were White, and two were African American. Patient diagnoses included anoxic brain injury, gastroschisis, omphalocele, end-stage renal disease, severe traumatic dog bites, gastric perforation, ventricular septal defect with congestive heart failure, congenital diaphragmatic hernia, ileal atresia, and thrombocytopenia with absent radius syndrome.

We recognized eight common consumer health-related needs among the caregivers of hospitalized pediatric patients, occurring frequently both within the consultations from these two research studies as well as consultations done outside of research studies. These needs are detailed in - Table 2 , with their semantic types and a summary of the typical interventions recommended by the consultation team for each type of need. Most parents expressed the need to communicate with multiple providers after hospital discharge. To address this need, the consultation service created an easy-to-read sheet that listed all providers, contact information, what medical problems they were managing, and upcoming scheduled appointments ( - Fig. 1). Parents were also registered for the institutional patient portal, My Health at Vanderbilt (MHAV), ${ }^{23}$ and were granted proxy access to their child's health information. The consultation team assisted parents in installing the patient portal on their devices and in navigating its functions.

Table 2 Most common health-related needs

\begin{tabular}{|c|c|c|}
\hline Need description & Need type & Recommendations \\
\hline $\begin{array}{l}\text { Need to communicate with multiple providers } \\
\text { after discharge from the hospital, to know who } \\
\text { their providers were, where they were located, } \\
\text { and how to contact them after being discharged; } \\
\text { for medically complex patients, which providers } \\
\text { to contact for which medical problems }\end{array}$ & Logistical - Contact/Communication & $\begin{array}{l}\text { Easy-to-read sheet clearly listing all providers, } \\
\text { their contact information, what medical } \\
\text { problems they were managing, and next } \\
\text { scheduled appointment } \\
\text { Registration for the institutional patient portal, } \\
\text { My Health at Vanderbilt, access to their child's } \\
\text { health information, and practice with the mes- } \\
\text { saging and appointment functions }\end{array}$ \\
\hline $\begin{array}{l}\text { Need to use medical devices (e.g., gastrostomy } \\
\text { tubes, tracheostomies) to administer care, } \\
\text { perform relevant procedures, and troubleshoot } \\
\text { problems }\end{array}$ & $\begin{array}{l}\text { Informational intervention - Technique/ } \\
\text { Administration }\end{array}$ & $\begin{array}{l}\text { Supplemental Web-based or mobile infor- } \\
\text { mation sites or videos for a variety of medical } \\
\text { devices (e.g., for gastrostomy tubes), a set of } \\
\text { videos from St. Louis Children's Hospital } \\
\text { (http://www.stlouischildrens.org/our-ser- } \\
\text { vices/general-surgery/video-caring-my-child- } \\
\text { with-gastrostomy) that cover common } \\
\text { questions and has separate device-specific } \\
\text { videos; sites were bookmarked on parents' } \\
\text { mobile devices or Web browsers }\end{array}$ \\
\hline $\begin{array}{l}\text { Need to distinguish normal or benign symptoms } \\
\text { (e.g., baby spit ups) from concerning signs or } \\
\text { symptoms related to the patients' medical } \\
\text { problems }\end{array}$ & $\begin{array}{l}\text { Informational problem - Clinical } \\
\text { presentation }\end{array}$ & $\begin{array}{l}\text { Web-based or mobile information resources } \\
\text { about the typical complaints in infancy and } \\
\text { childhood, such as the KidsDoc app from the } \\
\text { HealthyChildren.org sponsored by the } \\
\text { American Academy of Pediatrics (e.g., } \\
\text { https://www.healthychildren.org/english/ } \\
\text { tips-tools/apps/pages/default.aspx) }\end{array}$ \\
\hline Need to know what questions to ask & Logistical - Contact/Communication & $\begin{array}{l}\text { Question prompts lists, such as } 10 \text { Questions } \\
\text { You Should Know from the Agency for Health- } \\
\text { care Research and Quality (https://www.ahrq. } \\
\text { gov/patients-consumers/patient-involvement/ } \\
\text { ask-your-doctor/10questions.html) or AskMe3 } \\
\text { (http://www.npsf.org/page/askme3) from the } \\
\text { Institute for Healthcare Improvement and } \\
\text { National Patient Safety Foundation }\end{array}$ \\
\hline $\begin{array}{l}\text { Assistance with finding reliable health informa- } \\
\text { tion online }\end{array}$ & $\begin{array}{l}\text { Logistical - Health information } \\
\text { technology }\end{array}$ & $\begin{array}{l}\text { National Library of Medicine (NLM) Medline- } \\
\text { Plus video on Evaluating Internet Health } \\
\text { Information (https://medlineplus.gov/webe- } \\
\text { val/webeval.html) and Guide to Healthy Web } \\
\text { Surfing (https://medlineplus.gov/healthy- } \\
\text { websurfing.html) }\end{array}$ \\
\hline Need for information about the child's prognosis & Informational problem - Prognosis & $\begin{array}{l}\text { Disease-specific informational Web sites, } \\
\text { vetted by the primary or relevant consulting } \\
\text { care teams }\end{array}$ \\
\hline Need for emotional support & Social - Emotional need & $\begin{array}{l}\text { Disease-specific online or in-person support } \\
\text { groups, for example, Tennessee Parent to Par- } \\
\text { ent Matching Program (TNP2P), a state-funded } \\
\text { program that matches parents with trained } \\
\text { parent mentors who have a child who has gone } \\
\text { through a similar disease process (http://www. } \\
\text { tndisability.org/parent-matching) }\end{array}$ \\
\hline
\end{tabular}




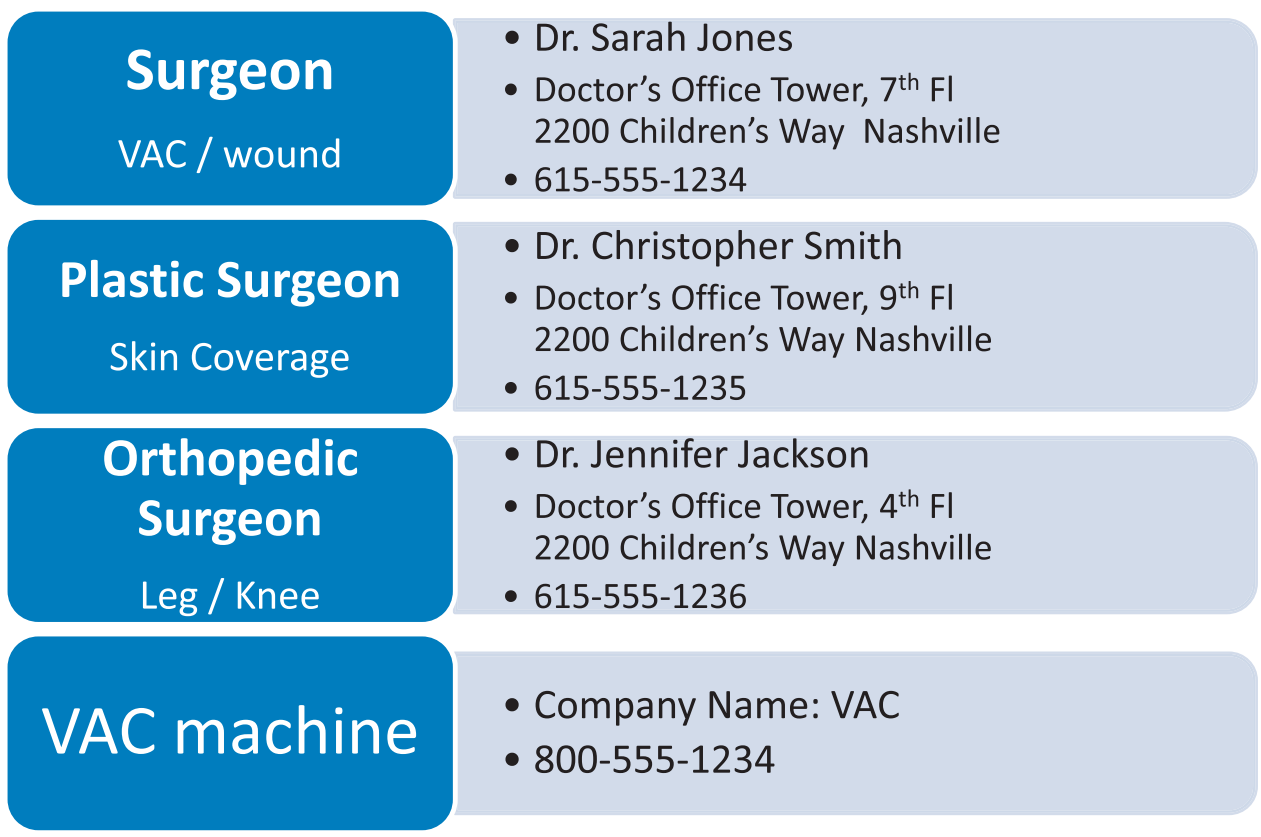

\section{My Health at Vanderbilt}

- Allows you to:

- Message Vanderbilt doctors

- Manage appointment visits

- Check results

- Find Medical Records

- 615-555-1237

\section{Appointments}

\section{- Date}

- April 26 $6^{\text {th }}, 2017$

- Call for an appointment!

\section{Time}

11:00am

\section{Doctor}

Dr. Jones

Dr. Jackson

Fig. 1 Streamlined discharge documentation.

Providers were asked to send messages to the parents through the portal before discharge, allowing parents to practice receiving and responding to messages.

Many of the patients went home with new medical devices, such as gastrostomy tubes or peritoneal dialysis catheters. At VCH, there are in-person educational programs for such devices. The consultation service provided additional supplemental materials from device-specific Web sites and videos. For example, St. Louis Children's Hospital has an excellent series of device-specific videos addressing common questions about gastrostomy tube care. ${ }^{24}$

A common need, especially among first-time parents, was distinguishing normal concerns in infancy or childhood (e.g., baby spit ups) from concerning signs or symptoms of the patients' medical problems. The consultation service pro- vided Web sites and apps with information on typical complaints in infancy and childhood ( - Table 1) and identified reliable sources of information on the patients' diseases.

One substantial contribution of engagement consultations was helping the parents articulate their questions. Many parents, especially those with low levels of education, health literacy, or activation, did not know what questions to ask. The consultation service recommended question prompt lists from patient advocacy sites ( - Table 1 ). Most parents also reported difficulty remembering their questions or answers given during fast-paced inpatient rounds. For this need, the consultation team recommended utilizing note pad apps or voice recording features present on nearly all mobile devices.

Nearly all parents had used Google searches for finding health information. Many expressed frustration at the overwhelming 
volume of information returned, medical jargon, and contradictory opinions. They stated or alluded to a need for assistance in identifying reliable sources of online information. For this need, parents were referred to online guides and tutorials for searching for health information online (-Table 1 ).

A common need for families confronted with new diagnoses was the need for information about their child's prognosis. Prognostic concerns varied widely and included questions about survival, functionality, quality of life, and long-term development. These needs were often unmet as they were not included with the acute issues addressed during inpatient rounds (e.g., vital signs, weight gain). For example, parents of an infant with thrombocytopenia and absent radii syndrome had many unanswered questions about whether the patient would be able to drive or write properly. The consultation team provided disease-specific informational resources for this child's rare disease and spent time to define and clarify the specific questions so they could be addressed by the primary team or specialty providers.

Most importantly, the consultation team recognized that uncertainty about prognosis was often associated with a social need for emotional support. Some wanted to learn from other families facing similar problems. For these needs, the consultation service provided information on vetted online or in-person support groups that were specific for each child's medical condition.

\section{Discussion}

We have implemented an Engagement Consultation Service to identify the health-related needs of the caregivers of hospitalized children and to provide recommendations to address these needs and promote engagement. This study informs the field of consumer health informatics by identifying the most common types of health-related needs reported in the pediatric inpatient setting and the technology-based interventions that can address them. Other studies of information needs of hospitalized patients and caregivers have identified some similar themes in the inpatient setting, ${ }^{25-28}$ but our consultation service focused specifically on addressing needs important for sustaining engagement after hospital discharge.

Our 3-year experience has revealed important and often unmet needs related to communication between the caregivers of the pediatric patients and their providers. Parents not only needed a means to contact multiple health care professionals, but also assistance in identifying who to contact for what problem. One of the most effective tools was the MHAV patient portal, but assistance with installation and practice using functionalities appeared to be critical to its success, even for technologically savvy parents. Parents who spent time using the portal during hospitalization were much more likely to use it after discharge, and some noted avoiding visits to the emergency department because they were able to discuss their concerns with health care providers through secure messaging in the patient portal. Our engagement consultation process supported the developmental process of activation by giving caregivers experience in accessing the portal so they had the knowledge and confidence to use it after going home. ${ }^{18}$ Significant reservations about implementing inpatient access to patient portals has been reported due to concerns about increased provider workload and workflow disruption, ${ }^{29-31}$ and our team experienced similar resistance. To address these concerns, we systematically educated all parents for whom the portal was recommended, introducing them to the individual functions and emphasizing the portal policies to set realistic expectations. $^{23}$ For example, the consultation team explained that test results might not be immediately available in the portal and that expected response times for secure messages was three business days, so portal messaging should not be used for urgent matters. Parents were usually educated in their hospital rooms, and they accessed the portal with their own devices. As demonstrated by others, ${ }^{32}$ providers' fears were eliminated after we gained experience with portal access during hospitalizations and educated families about appropriate portal usage.

Parents also needed support in remembering questions and knowing what questions to ask. Many parents do not ask questions out of fear of being labeled as "stupid" or "difficult" parents. ${ }^{33,34}$ Our consultation service addressed these needs with question lists from patient advocacy organizations, ${ }^{35}$ and many parents reported feeling more empowered. Such question prompt lists have been found to address core informational and decisional needs of patients and caregivers ${ }^{36}$ and should be considered as standard patient and caregiver education, especially for low-activation individuals or those new to health care systems. We also observed that simple tools, such as the note pad or voice recording apps built into most smartphones, were able to meet these needs. Further, regardless of socioeconomic status, most parents owned a smartphone with these basic functions. ${ }^{37}$ Parents were instructed how to use these apps on their own devices, and they were encouraged to employ them to log questions that occurred throughout the day and then access them during rounds to recall their questions and record the answers.

Another common need was comprehending the responsibilities of the multiple providers involved in their child's care. The disorienting inpatient experience can be overwhelming and decrease the ability to share in the decision making. ${ }^{38}$ Several groups have found excellent results in implementing a bedside tool to update patients and caregivers about the names and roles of their providers, ${ }^{39,40}$ and personal health records have helped to serve as a memory source. ${ }^{41}$ However, these tools often depend on access to a particular device, such as a tablet, or are only available at selected tertiary care institutions. The consultation service designed a single sheet that contained high-yield information for the parents: provider contact information, the medical problems those providers managed, and appointments ( - Fig. 1). Such information is available for extraction from most electronic health records, but is often buried in long discharge summaries with pages of preventative health recommendations. Such an easy-to-implement resource can be offered across the socioeconomic spectrum and may endure rapid evolution in technologies. 
Although our hospital has excellent educational programs, parents and caregivers benefited from having access to supplemental information regarding medical devices and disease prognosis. Randomized controlled trials have found that information provided from multiple modalities improved self-efficacy and health outcomes. ${ }^{42,43}$ Finally, most parents routinely used social media, but few had considered utilizing them for health. Many parents did not have strong social support, and disease-specific support groups on social media platforms were recommended. Prior work has demonstrated that patients and caregivers are willing to use these technologies for health. ${ }^{44}$ Although only a few parents reported joining the support groups, they appreciated knowing about them.

This report has several limitations. The consultation service was implemented at a large tertiary academic medical center with a robust informatics faculty, patient education experts, and student participants. We offer some generalizable lessons for addressing consumer health needs, but our comprehensive engagement interventions might be difficult to replicate in smaller centers. The consultations were also only offered to English-speaking families. Thus, our findings may not capture the full range of consumer health needs or effective solutions in minority populations. In addition, the consultation service is new and still evolving. As our experience and team grows, the types of needs we identify and the quality and diversity of the recommendations will change. Finally, although the iterative nature of the consultation process anecdotally supports the notion that the needs of families are being met, this case series does not provide data to substantiate that claim. Our ongoing research is evaluating the degrees to which needs are met and consultation recommendations are effective in satisfying needs; such data will be important to determine the impact of this innovative service.

\section{Conclusion}

This study enumerates recurring themes in the consumer health-related needs of the parents of hospitalized children and offers some important lessons for addressing those needs with health information technologies. The need for better ways to communicate with the health care team, both during hospitalizations and after discharge, was common. Although technologies to support communication were helpful, caregivers required assistance with installation and practice with usage to adopt these tools. Such practice supports parents in the developmental process of activation, giving them knowledge and confidence to take action independently. The caregivers of hospitalized children also frequently expressed needs for support in knowing what to ask, formulating specific questions, and remembering them during provider interactions. Simple and "low-tech" resources like smartphone note pads, question prompts, and focused summaries went a long way in meeting these needs and facilitating engagement. Such solutions are readily available, easy to replicate, and likely to endure the rapid evolution of technologies. Finally, consumers often had social and emotional needs associated with information needs. These needs frequently could be addressed by disease-specific support groups on social media tools. Most parents used social media regularly, but not for health-related purposes. Clinical informaticians can employ knowledge about the common needs of the caregivers of hospitalized pediatric patients to develop new technologies or to incorporate functions into existing consumer health tools such as patient portals and personal health records to meet these needs. Further research is needed to measure the impact of engagement consultations and recommended interventions on parent activation and pediatric health care outcomes.

\section{Clinical Relevance Statement}

This study reported the common health-related needs among the parents of hospitalized pediatric patients and the clinical information technologies recommended to address those needs and promote engagement.

\section{Multiple Choice Question}

Which of the following health-related needs were NOT commonly found among the parents of pediatric patients?

a. Need for an effective way to communicate with providers

b. Need for emotional support

c. Need for information on a particular diagnosis or complication

d. Need for information about how to use a smartphone

Correct Answer: The correct answer is option d, Need for information about how to use a smartphone.

\section{Protection of Human and Animal Subjects}

Both studies were performed in compliance with the World Medical Association Declaration of Helsinki on Ethical Principles for Medical Research Involving Human Subjects, and were approved by the Vanderbilt Children's Hospital Institutional Review Board.

\section{Funding}

This research was supported by a Vanderbilt Center for Effective Health Communication Research Grant, the National Institutes of Health National Library of Medicine [grant number 5T15LM007450-12], the National Institutes of Health National Center for Advancing Translational Sciences [grant UL1 TR000445], the Surgical Outcomes Center for Kids at Monroe Carell Jr. Children's Hospital, and the Section for Surgical Sciences at Vanderbilt University Medical Center.

Conflict of Interest

None.

\section{References}

1 Institute of Medicine. Crossing the Quality Chasm: A New Health System for the 21st Century. Washington, DC: National Academies Press; 2001

2 Stewart M, Brown JB, Donner A, et al. The impact of patientcentered care on outcomes. J Fam Pract 2000;49(09):796-804 
3 Little P, Everitt H, Williamson I, et al. Observational study of effect of patient centredness and positive approach on outcomes of general practice consultations. BMJ 2001;323(7318):908-911

4 Maeng DD, Graf TR, Davis DE, Tomcavage J, Bloom FJ Jr. Can a patient-centered medical home lead to better patient outcomes? The quality implications of Geisinger's ProvenHealth Navigator. Am J Med Qual 2012;27(03):210-216

5 Wolf DM, Lehman L, Quinlin R, Zullo T, Hoffman L. Effect of patient-centered care on patient satisfaction and quality of care. J Nurs Care Qual 2008;23(04):316-321

6 Wanzer MB, Booth-Butterfield M, Gruber K. Perceptions of health care providers' communication: relationships between patientcentered communication and satisfaction. Health Commun 2004; 16(03):363-383

7 Hibbard JH, Greene J. What the evidence shows about patient activation: better health outcomes and care experiences; fewer data on costs. Health Aff (Millwood) 2013;32(02):207-214

8 Maly RC, Bourque LB, Engelhardt RF. A randomized controlled trial of facilitating information giving to patients with chronic medical conditions: effects on outcomes of care. J Fam Pract 1999;48(05): 356-363

9 Hibbard JH, Greene J, Overton V. Patients with lower activation associated with higher costs; delivery systems should know their patients' 'scores'. Health Aff (Millwood) 2013;32(02):216-222

10 Hibbard JH, Greene J, Sacks RM, Overton V, Parrotta C. Improving population health management strategies: identifying patients who are more likely to be users of avoidable costly care and those more likely to develop a new chronic disease. Health Serv Res 2017;52(04):1297-1309

11 Bollinger LM, Nire KG, Rhodes MM, Chisolm DJ, O'Brien SH. Caregivers' perspectives on barriers to transcranial Doppler screening in children with sickle-cell disease. Pediatr Blood Cancer 2011;56(01):99-102

12 Hommel KA, Denson LA, Baldassano RN. Oral medication adherence and disease severity in pediatric inflammatory bowel disease. Eur J Gastroenterol Hepatol 2011;23(03):250-254

13 Nicholson O, Mellins C, Dolezal C, Brackis-Cott E, Abrams EJ. HIV treatment-related knowledge and self-efficacy among caregivers of HIV-infected children. Patient Educ Couns 2006;61 (03):405-410

14 Warren JS, Brown CR, Layne CM, Nelson PL. Parenting self-efficacy as a predictor of child psychotherapy outcomes in usual care: a multidimensional approach. Psychother Res 2011;21(01):112-123

15 American Hospital Association. Fast Facts on US Hospitals 2017; January 2, 2017. Available at: http://www.aha.org/research/rc/ stat-studies/fast-facts.shtml. Accessed May 2, 2017

16 Collins S, Dykes P, Bates DW, et al. An informatics research agenda to support patient and family empowerment and engagement in care and recovery during and after hospitalization. J Am Med Inform Assoc 2018;25(02):206-209

17 Jackson GP, Robinson JR, Ingram E, et al. A technology-based patient and family engagement consult service for the pediatric hospital setting. J Am Med Inform Assoc 2018;25(02):167-174

18 Hibbard JH, Stockard J, Mahoney ER, Tusler M. Development of the Patient Activation Measure (PAM): conceptualizing and measuring activation in patients and consumers. Health Serv Res 2004;39 (4 Pt 1):1005-1026

19 Cronin RM, Fabbri D, Denny JC, Jackson GP. Automated classification of consumer health information needs in patient portal messages. AMIA Annu Symp Proc 2015;2015:1861-1870

20 Shenson JA, Ingram E, Colon N, Jackson GP. Application of a consumer health information needs taxonomy to questions in maternal-fetal care. AMIA Annu Symp Proc 2015;2015:1148-1156

21 Cronin RM, Fabbri D, Denny JC, Rosenbloom ST, Jackson GP. A comparison of rule-based and machine learning approaches for classifying patient portal messages. Int J Med Inform 2017; 105:110-120
22 Robinson JR, Valentine A, Carney C, Fabbri D, Jackson GP. Complexity of medical decision-making in care provided by surgeons through patient portals. J Surg Res 2017;214:93-101

23 Osborn CY, Rosenbloom ST, Stenner SP, et al. MyHealthAtVanderbilt: policies and procedures governing patient portal functionality. J Am Med Inform Assoc 2011;18(Suppl 1):i18-i23

24 Video: Caring for My Child with a Gastrostomy; 2018. Available at: http://www.stlouischildrens.org/our-services/general-surgery/ video-caring-my-child-with-gastrostomy. Accessed June 30, 2018

25 Caligtan CA, Carroll DL, Hurley AC, Gersh-Zaremski R, Dykes PC. Bedside information technology to support patient-centered care. Int J Med Inform 2012;81(07):442-451

26 Kaziunas E, Hanauer DA, Ackerman MS, Choi SW. Identifying unmet informational needs in the inpatient setting to increase patient and caregiver engagement in the context of pediatric hematopoietic stem cell transplantation. J Am Med Inform Assoc 2016;23(01):94-104

27 Kendall L, Mishra SR, Pollack A, Aaronson B, Pratt W. Making background work visible: opportunities to address patient information needs in the hospital. AMIA Annu Symp Proc 2015; 2015:1957-1966

28 Miller AD, Mishra SR, Kendall L, Haldar S, Pollack AH, Pratt W. Partners in Care: Design Considerations for Caregivers and Patients During a Hospital Stay, CSCW: Proceedings of the Conference on Computer-Supported Cooperative Work. Conference on Computer-Supported Cooperative Work 2016; 2016:756-769

29 Miller DP Jr, Latulipe C, Melius KA, Quandt SA, Arcury TA. Primary care providers' views of patient portals: interview study of perceived benefits and consequences. J Med Internet Res 2016;18(01):e8

30 Keplinger LE, Koopman RJ, Mehr DR, et al. Patient portal implementation: resident and attending physician attitudes. Fam Med 2013;45(05):335-340

31 Carayon P, Hoonakker P, Cartmill R, Hassol A. Using Health Information Technology (IT) in Practice Redesign: Impact of Health IT on Workflow, Patient-Reported Health Information Technology and Workflow (Prepared by Abt Associated under Contract No. 2902010-00031I). AHRQ Publication No. 15-0043-EF. Rockville, MD: Agency for Healthcare Research and Quality May 2015

32 Kelly MM, Dean SM, Carayon P, Wetterneck TB, Hoonakker PL. Healthcare team perceptions of a portal for parents of hospitalized children before and after implementation. Appl Clin Inform 2017;8(01):265-278

33 Frosch DL, May SG, Rendle KA, Tietbohl C, Elwyn G. Authoritarian physicians and patients' fear of being labeled 'difficult' among key obstacles to shared decision making. Health Aff (Millwood) 2012; 31(05):1030-1038

34 Adams JR, Elwyn G, Légaré F, Frosch DL. Communicating with physicians about medical decisions: a reluctance to disagree. Arch Intern Med 2012;172(15):1184-1186

35 "Be More Involved with Your Health Care." Agency for Healthcare Research and Quality. Available at: https://www.ahrq.gov/ patients-consumers/patient-involvement/ask-your-doctor/tipsand-tools/beinvolved.html. Accessed January 10, 2017

36 Steffens NM, Tucholka JL, Nabozny MJ, Schmick AE, Brasel KJ, Schwarze ML. Engaging patients, health care professionals, and community members to improve preoperative decision making for older adults facing high-risk surgery. JAMA Surg 2016;151 (10):938-945

37 "Record shares of Americans now own smartphones, have home broadband." Pew Research Center. Available at: http://www.pewresearch.org/fact-tank/2017/01/12/evolution-of-technology/. Accessed February 10, 2017

38 Morris D, Karlson A. Dynamic Accessibility Requirements for Hospital Patients, SIGCHI Conference on Human Factors in Computing Systems. Vancouver, BC, Canada: ACM Press; 2011

39 O'Leary KJ, Lohman ME, Culver E, Killarney A, Randy Smith G Jr, Liebovitz DM. The effect of tablet computers with a mobile patient 
portal application on hospitalized patients' knowledge and activation. J Am Med Inform Assoc 2016;23(01):159-165

40 Vawdrey DK, Wilcox LG, Collins SA, et al. A tablet computer application for patients to participate in their hospital care. AMIA Annu Symp Proc 2011;2011:1428-1435

41 Cimino JJ, Patel VL, Kushniruk AW. The patient clinical information system (PatCIS): technical solutions for and experience with giving patients access to their electronic medical records. Int J Med Inform 2002;68(1-3):113-127
42 Stevens VJ, Glasgow RE, Hollis JF, Lichtenstein E, Vogt TM. A smoking-cessation intervention for hospital patients. Med Care 1993;31(01):65-72

43 Mahler HI, Kulik JA. Effects of preparatory videotapes on selfefficacy beliefs and recovery from coronary bypass surgery. Ann Behav Med 1998;20(01):39-46

44 Chennupati S, Dorst M, Anders SH, Jackson GP. Technology usage and preferences during pregnancy. Poster presentation at the AMIA 2016 Annual Symposium, Chicago, IL, November 14, 2016 